\title{
Enhancement of Residual Arylsulfatase B Activity in Feline Mucopolysaccharidosis VI by Thiol-induced Subunit Association
}

\author{
Deborah T. Vine, Margaret M. McGovern, Edward H. Schuchman, Mark E. \\ Haskins, and Robert J. Desnick, Division of Medical Genetics, Mount Sinai \\ School of Medicine, New York 10029; Sections of Pathology and Medical \\ Genetics, University of Pennsylvania School of Veterinary Medicine, and the \\ University of Pennsylvania Genetics Center, Philadelphia, Pennsylvania \\ 19104
}

A B S TRACT The molecular pathology of the deficient arylsulfatase B activity in feline mucopolysaccharidosis (MPS) VI was investigated. Compared with the highly purified normal feline hepatic enzyme, the purified MPS VI residual activity had a 100-fold higher Michaelis constant $\left(\mathbf{K}_{\mathrm{m}}\right)$, an altered electrophoretic mobility, half the apparent native molecular weight, and markedly decreased thermo-, cryo-, and $\mathrm{pH}$ stabilities. Molecular weight and alkylation studies were consistent with the normal enzyme being a homodimer and the residual MPS VI enzyme a monomer. When incubated with various sulfhydryl reagents, the residual specific activity was enhanced several-fold, whereas the activity of the purified normal enzyme was unaffected or slightly inhibited. In the presence of dithiothreitol (DTT) and cysteamine, a lysosomotropic aminothiol, the residual activity had an electrophoretic mobility and native molecular weight similar to those of the normal feline enzyme. These findings suggested that the monomeric residual enzyme was dimerized in the presence of thiol-reducing agents. To determine if thiol-induced subunit association could therapeutically increase the residual activity and degrade the accumulated dermatan sulfate, in vitro and in vivo experiments were undertaken. When $2 \mathrm{mM}$ DTT or cysteamine was incubated with heparinized whole blood from an MPS VI cat, the leukocyte residual arylsulfatase B activity increased 11- and 20-fold, respectively, and the accumulated dermatan sulfate was degraded in the presence of both thiol reagents. Intravenous administration of DTT $(50 \mathrm{mg} / \mathrm{kg})$ effected an immediate, but transient, increase in leukocyte re-

Received for publication 25 August 1981 and in revised form 19 October 1981. sidual activity; however, the substrate levels were not significantly decreased. In contrast, intravenous administration of cysteamine $(15 \mathrm{mg} / \mathrm{kg})$ increased leukocyte residual activity more than sixfold $30 \mathrm{~min}$ postinfusion; concomitantly, the leukocyte substrate was decreased to $35 \%$ of the initial level immediately after infusion and to about $45 \%$ of preinfusion values during the 120-min period studied. These results suggest that the defective residual activity in feline MPS VI can be therapeutically manipulated by thiol-induced subunit association. Furthermore, this animal analog provides a prototype for the investigation of human inborn errors of metabolism resulting from enzymatic defects that might be amenable to enzyme manipulation therapy.

\section{INTRODUCTION}

Dermatan sulfate mucopolysaccharidosis (MPS VI), ${ }^{1}$ a lysosomal storage disease resulting from the deficient activity of arylsulfatase B (ASB; EC 3.1.6.1), has been described in humans (Maroteaux-Lamy disease) (1-4) and, more recently, in Siamese cats (5-7). The feline analog and the human disorder are characterized by severe dysostosis multiplex, "Hurler-like" facial dysmorphia, short stature, corneal opacities, vacuolated lymphocytes and neutrophils, normal neurologic function, and autosomal recessive inheritance (1-7). Although affected human and feline homozygotes have $\sim 6 \%$ of normal ASB activity $(2,3,5-9)$, the residual activity is insufficient and its pathologic substrate, der-

${ }^{1}$ Abbreviations used in this paper: ASB, arylsulfatase B; DTT, dithiothreitol; MPS mucopolysaccharidosis; $p$ NCS, $p$ nitrocatechol sulfate. 
TABLE I

Comparative Kinetic and Physical Properties of Highly Purified Arylsulfatase B From Feline MPS VI, Normal Feline, and Normal Human Liver

\begin{tabular}{|c|c|c|c|}
\hline Property & Feline MPS VI• & Normal feline ${ }^{\bullet}$ & Normal humant \\
\hline Specific activity, $\mathrm{nmol} / \mathrm{h} / \mathrm{mg}$ & 2,750 & 106,000 & 800,000 \\
\hline Purification, -fold & 1,880 & 2,840 & 8,400 \\
\hline pH Optimum & 5.7 & 5.7 & 5.7 \\
\hline Apparent $\mathrm{Km}, \mathrm{mM}$ for $p N C S$ & 50 & 0.5 & 3.6 \\
\hline Apparent $\mathrm{V}_{\max }, n m o l / h / m g$ & 1,962 & 3,967 & 5,100 \\
\hline Thermostability, $\mathrm{t}_{1 / 2}$ at $60^{\circ} \mathrm{C}, \min$ & 5 & 50 & 30 \\
\hline Electrophoretic mobility, $R_{\mathrm{m}}$ on PAGE & 0.32 & 0.74 & 0.86 \\
\hline pI & - & 7.8 & 8.0 \\
\hline \multicolumn{4}{|l|}{ Cryostability, \% initial activity after 72} \\
\hline$h,-50^{\circ} \mathrm{C}$ & 42 & 85 & 85 \\
\hline pH Stability range & $4.5-7.5$ & $3.5-8.5$ & $3.5-8.5$ \\
\hline Molecular weight, Sephadex G-200 & 53,000 & 110,000 & 48,000 \\
\hline SDS PAGE & - & 41,000 & 38,000 \\
\hline
\end{tabular}

- Data summarized from reference 10.

t Data summarized from reference 11 .

matan sulfate, accumulates in various tissues and fluids (1-7). Because the feline disease provides a unique model for characterization of the enzymatic defect and for the development and evaluation of experimental therapeutic strategies, an improved enzymatic method has been used to identify heterozygotes (9) for efficient breeding of affected animals.

Recently, we purified the residual ASB activity from feline MPS VI liver (10), as well as the normal feline and human hepatic isozymes for comparison. ${ }^{2}$ As summarized in Table I, many of the physical and kinetic properties of the normal feline and human enzymes were similar. However, electrophoretic and isoelectric focusing studies revealed the homogeneous feline enzyme to be more electronegative than the homogeneous human isozyme. In addition, molecular weight and subunit alkylation studies were consistent with the normal feline enzyme being a homodimer, whereas the normal human isozyme appeared to be a monomer $(10,11)$. Intriguingly, the residual ASB, partially purified from feline MPS VI liver, was found to be a monomer that had an apparent $\mathrm{K}_{\mathrm{m}}$ value for the synthetic substrate, $p$-nitrocatechol sulfate ( $p$ NCS), at least 100 -fold greater than that for the normal feline enzyme (10).

Because the purified MPS VI residual activity was more cryolabile, thermolabile, and $\mathrm{pH}$ sensitive than the normal feline enzyme (Table I), an evaluation of various reagents, including sulfhydryl-reactive com-

\footnotetext{
${ }^{2}$ McGovern, M. M., D. T. Vine, M. E. Haskins, and R. J. Desnick. Manuscript in review.
}

pounds, was undertaken in an attempt to increase the stability of the residual enzyme. In this communication, we report the enhancement of the feline MPS VI residual ASB activity by thiol-induced subunit reassociation, as well as the effect of dithiothreitol (DTT) and cysteamine on the residual activity and dermatan sulfate catabolism in the feline model.

\section{METHODS}

Specimen collection and materials. Livers from normal and affected Siamese cats were removed immediately after the animals were killed and stored at $-50^{\circ} \mathrm{C}$. Mixed leukocytes were isolated from heparinized whole blood by dextran sedimentation as described (12). DTT was purchased from Calbiochem-Behring Corp., American Hoechst Corp., San Diego, Calif. Cysteamine, cystamine, iodoacetate, iodoacetamide, $p$-chloromercuribenzoate, $p N C S$, and 1-Omethyl- $\alpha$-D-glucopyranoside were obtained from Sigma Chemical Co., St. Louis, Mo. Mercaptoethanol was from Eastman Kodak Co., Rochester, N. Y. The Bio-Rad protein assay and materials for polyacrylamide gel electrophoresis were from Bio-Rad Laboratories, Richmond, Calif. Pronase from Streptomyces griseus was purchased from Boehringer Mannheim Biochemicals, Indianapolis, Ind. Fluorescamine was obtained from Hoffman-LaRoche, Inc., Nutley, N. J. EDTA tetrasodium salt was from Fisher Scientific Co., Fairlawn, N. J., and LiCl was from Mallinckrodt, Inc., Paris, KT. Alcian blue 8GN was obtained from MCB Reagents, Cincinnati, Ohio. DEAE-cellulose was obtained from Whatman, Inc., Clifton, N. J. Concanavalin A-Sepharose, Sephadex G200 , and molecular weight standards (aldolase, bovine serum albumin, ovalbumin, chymotrypsinogen, and cytochrome C) were obtained from Pharmacia Fine Chemicals, Piscataway, N. J. Cellulose acetate gels $(14.5 \times 5.5 \mathrm{~cm} ; 250 \mu \mathrm{m}$ thick) were from Kalex Scientific Co., Inc., Manhasset, N. Y. Ac- 
rodisc filters were purchased from Gelman Scientific, Inc., Ann Arbor, Mich. and Amicon ultrafiltration apparatus and membranes were from Amicon Corp., Lexington, Mass. The microzone electrophoretic cell (model R-101) and Duostat power supply for cellulose acetate electrophoresis were obtained from Beckman Instruments, Inc., Fullerton, Calif. All other reagents were of highest grade available.

Enzyme assays. ASB activity was determined as described $(9,10)$ using the synthetic substrate, $p$ NCS. Final substrate concentrations of 5 and $20 \mathrm{mM} p$ NCS were used to assay the normal and MPS VI activities, respectively. All assays were performed in triplicate. $1 \mathrm{U}$ of enzymatic activity was equal to that amount of enzyme that hydrolyzed 1 $\mathrm{nmol}$ of substrate per hour at $37^{\circ} \mathrm{C}$. Protein was determined by the Bio-Rad assay according to the manufacturer's instructions (13).

Purification of hepatic ASB. ASB from normal feline and feline MPS VI livers was purified as described $(10,11)$, with final sp act of 106,000 and $2,750 \mathrm{U} / \mathrm{mg}$ protein, respectively. These highly purified preparations were used to study the effect of various sulfhydryl reagents on their physical and kinetic properties. Other studies were performed on less highly purified hepatic ASB preparations that were isolated by homogenization of normal and MPS VI liver samples ( 5

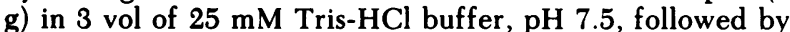
centrifugation at $27,000 \mathrm{~g}$ for $45 \mathrm{~min}$. The samples were

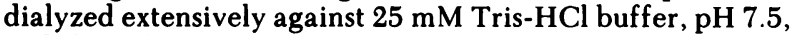
and then chromatographed on DEAE-cellulose columns $(20$ $\times 1.5 \mathrm{~cm}$ ), which had previously been equilibrated with the same buffer. After sample application, the columns were washed with $60 \mathrm{ml}$ of buffer and then a linear $\mathrm{NaCl}$ gradient $(0-0.3 \mathrm{M})$ was applied. Fractions $(2.5 \mathrm{ml})$ were collected at a flow rate of $0.4 \mathrm{ml} / \mathrm{min}$ and assayed for ASB activity. DEAE-cellulose chromatography resulted in complete separation of ASB from arylsulfatase A. The specific activities of the normal and residual MPS VI preparations were 343.8 and $23.9 \mathrm{U} / \mathrm{mg}$ protein, respectively.

Dermatan sulfate quantitation. Dermatan sulfate levels were determined by cellulose acetate electrophoresis according to the procedure of Schuchman and Desnick (14). Briefly, the leukocyte pellets were subjected to pronase digestion (final concentration $0.5 \mathrm{mg} / \mathrm{ml}$ ) at $60^{\circ} \mathrm{C}$ for $2 \mathrm{~h}$. Protein was subsequently assayed by the fluorescamine method (15). Aliquots of each sample containing $200 \mu \mathrm{g}$ of protein were applied to cellulose acetate gels and electrophoresis was performed for $50 \mathrm{~min}$ at $4^{\circ} \mathrm{C}(2.5 \mathrm{~mA} / \mathrm{cm}$ gel width; $15 \mathrm{~V} / \mathrm{cm}$ gel length) using an electrolyte solution containing $10 \mathrm{mM}$ EDTA tetrasodium salt and $50 \mathrm{mM} \mathrm{LiCl}$ at $\mathrm{pH}$ 8.4. After electrophoresis, the gels were stained for $1 \mathrm{~min}$ in $0.1 \%$ alcian blue $8 \mathrm{GN}$ at $23^{\circ} \mathrm{C}$. Destaining was accomplished by two serial submersions in $100 \mathrm{ml}$ of $2 \%$ glacial acetic acid for $5 \mathrm{~min}$ each. The dermatan sulfate bands were quantitated by a modification of the procedure described by Kimura et al. (16). Each band was cut out and immersed in $2.0 \mathrm{ml}$ of chloroform/methanol $9: 1$ ( $\mathrm{vol} / \mathrm{vol}$ ), which dissolved the cellulose acetate. The absorbance of the solution was determined spectrophotometrically at $625 \mathrm{~nm}$. For control, blank gel slices of the same size were dissolved and their absorbance determined. The standard curve for dermatan sulfate was linear over a range of 1 to $5 \mu \mathrm{g}$.

Effect of sulfhydryl reagents on the physiokinetic properties of purified ASB. Highly purified normal feline and feline MPS VI ASB activities were determined in the presence and absence of various concentrations of sulfhydrylreactive agents in $25 \mathrm{mM}$ Tris- $\mathrm{HCl}$ buffer, $\mathrm{pH}$ 7.5. Kinetic studies were performed at $\mathrm{pH} 7.5$, the $\mathrm{pH}$ optimum for both enzymes, in the presence and absence of $0.25 \mathrm{mM}$ DTT.
Thermostability (at $60^{\circ} \mathrm{C}$ ) and cryostability (after $72 \mathrm{~h}$ at $-50^{\circ} \mathrm{C}$ ) of the normal and residual enzymes were determined with and without $0.25 \mathrm{mM}$ DTT. The effect of $\mathrm{pH}$ (3.5-8.5) on the stability of the normal and MPS VI residual activities was compared by incubating the purified enzymes for $1 \mathrm{~h}$ at $37^{\circ} \mathrm{C}$ in the presence and absence of $0.25 \mathrm{mM}$ DTT in $0.14 \mathrm{M}$ sodium acetate- $0.14 \mathrm{M}$ sodium barbital buffer, adjusted to the desired $\mathrm{pH}$ with $\mathrm{HCl}$.

Analytical polyacrylamide gel electrophoresis was performed in $7 \%$ disc gels $(0.5 \times 7.0 \mathrm{~cm})$ in $100 \mathrm{mM} \beta$-alanineacetate buffer at pH 4.0 as described by Reisfeld et al. (17). Partially purified normal feline and feline MPS VI ASB were electrophoresed in the presence and absence of $1.0 \mathrm{mM}$ DTT at a constant current of $4 \mathrm{~mA} /$ gel for $3 \mathrm{~h}$ or until the tracking dye reached the bottom of the tube. The gels were stained for ASB activity using $p$ NCS as described (10). Apparent molecular weight values for each enzyme were determined in the presence and absence of $1.0 \mathrm{mM}$ DTT on $5,6,7$, and $8 \%$ native polyacrylamide gels according to the method of Hendrick and Smith (18). Aldolase (mol wt 158,000), bovine serum albumin $(68,000)$, chymotrypsinogen $(24,000)$, and cytochrome $C(12,400)$ were used as standards. Apparent molecular weights were also estimated by gel filtration on Sephadex G-200 using a $1.5 \times 100-\mathrm{cm}$ column in the presence and absence of $1.0 \mathrm{mM}$ DTT in the enzyme sample and elution buffer. Aldolase, bovine serum albumin, ovalbumin (mol wt 45,000), and chymotrypsinogen were used as standards.

In vitro studies. The effect of DTT, cysteamine, and cystamine on ASB activity and dermatan sulfate levels was determined in leukocytes isolated from $30 \mathrm{ml}$ of heparinized whole blood obtained from normal and MPS VI cats. Varying concentrations of each sulfhydryl reagent, freshly prepared in $25 \mathrm{mM}$ Tris- $\mathrm{HCl}$ buffer, $\mathrm{pH} \mathrm{7.4,} \mathrm{was} \mathrm{added} \mathrm{to} 5-\mathrm{ml}$ aliquots of whole blood in $13 \times 100-\mathrm{mm}$ screw-cap tubes. The tubes were sealed after gassing with $\mathrm{N}_{2}$ and the suspensions were gently mixed on a rocking platform for $1 \mathrm{~h}$ at $37^{\circ} \mathrm{C}$. Then the leukocytes were isolated by dextran sedimentation, washed twice with $0.15 \mathrm{M} \mathrm{NaCl}$, suspended in $0.5 \mathrm{ml}$ of distilled water, and lysed by three cycles of freeze/thaw $\left(-70 / 37^{\circ} \mathrm{C}\right)$. Aliquots $(50 \mu \mathrm{l})$ were removed from each leukocyte homogenate for determination of the dermatan sulfate concentrations and the remainder of the homogenate was centrifuged at $10,000 \mathrm{~g}$ for $10 \mathrm{~min}$. The supernatant was removed, arylsulfatase A and ASB were separated by batch DEAE-cellulose chromatography as described (9), and the ASB activities and protein concentrations were determined.

In vivo studies. DTT $(50 \mathrm{mg} / \mathrm{kg})$ or cysteamine $(15 \mathrm{mg} /$ $\mathrm{kg}$ ) was dissolved in $10 \mathrm{ml}$ of sterile $0.15 \mathrm{M} \mathrm{NaCl}$ and passed through an Acrodisc filter (0.2-micron pore size) immediately before use. DTT or cysteamine was intravenously administered over $10 \mathrm{~min}$ into an 18-mo-old MPS VI female $(2.27 \mathrm{~kg})$ cat and her normal female sibling $(3.27 \mathrm{~kg})$. Heparinized blood samples $(5 \mathrm{ml})$ were obtained immediately before and at $0-, 30-, 60-$, and 120 -min intervals after infusion. ASB activity and dermatan sulfate levels were determined in isolated leukocytes as described above. The volume of blood drawn for these studies precluded the assessment of multiple experimental infusions.

\section{RESULTS}

Effect of sulfhydryl reagents on highly purified normal and MPS VI ASB. Table II summarizes the effect of varying concentrations of selected sulfhydrylreactive compounds on the highly purified normal fe- 
line and feline MPS VI residual ASB activities. The thiol-reducing compounds, DTT and cysteamine, had a marked stimulatory effect on the residual activity. For example, DTT, at concentrations ranging from 0.025 to $0.25 \mathrm{mM}$, increased the MPS VI residual hepatic activity about fourfold; at higher DTT concentrations less stimulation was obtained. In marked contrast, DTT had no effect or slightly inhibited the purified normal enzyme. In addition, similar concentrations of alkylating or other reducing agents consistently resulted in stimulation of the residual activity, whereas the normal enzyme was not affected or was slightly inhibited. The greatest enhancement was obtained with $0.25 \mathrm{mM}$ DTT and $0.25 \mathrm{mM}$ cysteamine (4- and 12-fold, respectively). The inhibitory effect of EDTA on the residual activity (Table II) indicated that the depletion of divalent cations was not the mechanism responsible for residual enzyme stimulation.

The effect of DTT on the physical and kinetic properties of the highly purified normal feline and feline MPS VI hepatic ASB enzymes is summarized in Table III. DTT had essentially no effect on all the properties of the normal feline enzyme studied. However, DTT altered the specific activity, apparent $\mathrm{V}_{\max }$, electro- phoretic mobility, and apparent native molecular weight values of the highly purified MPS VI residual activity. Although the apparent $K_{m}$ value of the residual activity was unchanged in the presence of DTT, this thiol-reducing agent increased the apparent $V_{\max }$ about threefold (Fig. 1). Analytical polyacrylamide gel electrophoresis of the residual feline activity in the presence of $1.0 \mathrm{mM}$ DTT (Fig. 2) or $1.0 \mathrm{mM}$ cysteamine (data not shown) resulted in the migration of the residual ASB to a position similar to that of the normal enzyme, which was not changed by the presence of DTT. DTT had no effect on the altered thermo-, cryo-, or pH-stabilities of the residual MPS VI enzyme.

Most intriguingly, the apparent native molecular weight values of the residual enzyme were essentially the same as those of the normal enzyme when estimated in the presence of $1.0 \mathrm{mM}$ DTT by gel filtration or by analytical polyacrylamide gel electrophoresis using increasing acrylamide concentrations according to the procedure of Hendrick and Smith (18). Analysis of the latter studies indicated that the two native enzymes had the same apparent molecular weight values (Fig. 3B) and similar, but not identical charges in the

TABLE II

Effect of Various Thiol Reagents and EDTA on Highly Purified Normal Feline and Feline MPS VI Arylsulfatase B Activities

\begin{tabular}{lccc}
\hline \multicolumn{1}{c}{ Thiol reagent } & Concentration & Normal feline & Feline MPS VI \\
\hline \multirow{2}{*}{ None } & $m M$ & \multicolumn{2}{c}{ \% Initial activity $^{\circ}$} \\
DTT & & 100 & 100 \\
& 0.025 & 102 & 411 \\
Cysteamine & 0.25 & 90 & 420 \\
& 2.5 & 77 & 154 \\
Mercaptoethanol & 0.025 & 96 & 270 \\
p-Chloromercuribenzoate & 0.25 & 95 & 1200 \\
Iodoacetate & 2.5 & 81 & 800 \\
Iodoacetamide & 0.25 & 86 & 197 \\
EDTA & 0.25 & 92 & 152 \\
& 0.25 & 78 & 152 \\
& 0.25 & 82 & 147 \\
& 5 & 92 & 74 \\
& 250 & 87 & 62 \\
\hline
\end{tabular}

- Initial activities of the normal feline and feline MPS VI residual enzymes were 313.1 and $20.3 \mathrm{nmol} / \mathrm{h}$ per $\mathrm{ml}$, respectively. An aliquot of each enzyme $(0.1 \mathrm{ml})$ was mixed with each sulfhydryl reagent in $25 \mathrm{mM}$ Tris- $\mathrm{HCl}$ buffer, $\mathrm{pH} 7.5$, to achieve the indicated final concentration. The solutions were gassed with nitrogen, mixed for $10 \mathrm{~min}$, and then assayed by the standard procedure. 
TABLE III

Effect of DTT on the Properties of Highly Purified Normal and MPS VI Residual Arylsulfatase B Activities

\begin{tabular}{|c|c|c|c|}
\hline Property & $\begin{array}{l}\text { Feline MPS } \\
\text { VI }\end{array}$ & $\begin{array}{l}\text { Feline MPS } \\
\text { VI +DTT• }\end{array}$ & $\begin{array}{l}\text { Normal feline } \\
\pm D^{\circ T T}\end{array}$ \\
\hline $\begin{array}{l}\text { Electrophoretic mobility, } R_{m} \text { on PAGE } \\
\text { Cryostability } \% \text { initial activity after } 72 \text {. }\end{array}$ & 0.32 & 0.65 & 0.74 \\
\hline $\begin{array}{l}\text { Cryostability, \% initial activity after } 72 \mathrm{~h} \text {, } \\
-50^{\circ} \mathrm{C}\end{array}$ & 42 & 43 & 85 \\
\hline Thermostability, $t_{1 / 2}$ at $60^{\circ} \mathrm{C}$; $\min$ & 5 & 5 & 50 \\
\hline pH Stability range & $4.5-7.5$ & $4.5-7.5$ & $3.5-8.5$ \\
\hline$K_{m}, m M$ for $p N C S$ & 50 & 50 & 0.5 \\
\hline $\mathrm{V}_{\max }, n m o l / h / m g$ & 1,962 & 5,880 & 3,967 \\
\hline Molecular weight, Sephadex G-200 & 53,000 & 100,000 & 110,000 \\
\hline Native PAGE & 80,000 & 166,000 & 166,000 \\
\hline
\end{tabular}

- The physical and kinetic properties were determined in the absence and presence of $0.25 \mathrm{mM}$ DTT with the exception of the molecular weight studies, which were performed with and without $1.0 \mathrm{mM}$ DTT. The specific activities of the normal and residual MPS VI preparations used for the kinetic studies were 106,000 and $2,750 \mathrm{U} / \mathrm{mg}$ protein, respectively.

presence of DTT (Fig. 3A). In the absence of DTT, the molecular weight data were consistent with the residual MPS VI enzyme having approximately half the apparent molecular weight of the normal enzyme; additionally, in the absence of the thiol-reducing
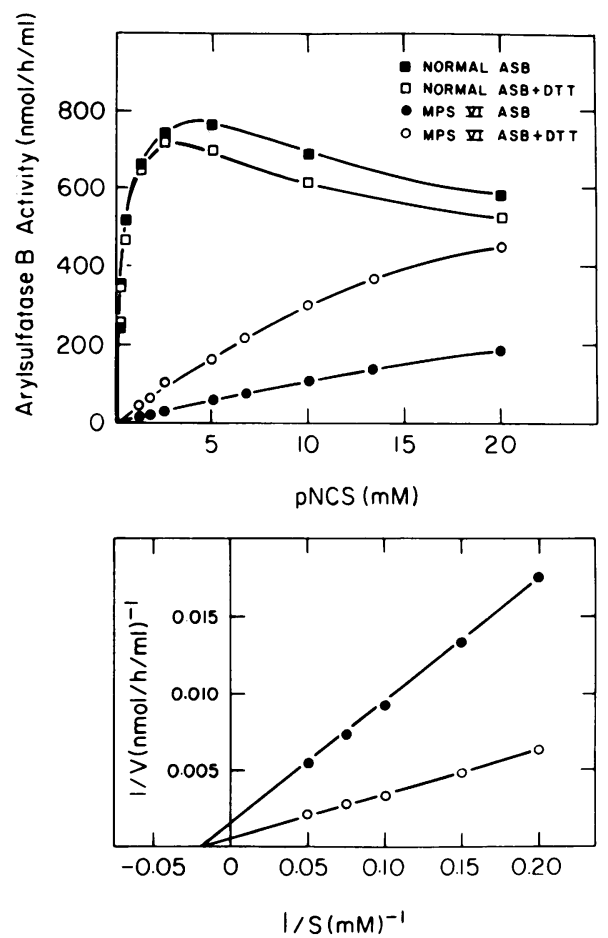

Figure 1 Effect of substrate concentration on normal and feline MPS VI hepatic ASB activities \pm DTT. (upper panel) Velocity vs. pNCS concentration. (lower panel) LineweaverBurk plots. (- MPS VI ASB; $\mathrm{O}-\mathrm{O}$ MPS VI ASB + DTT) agent, the untreated enzymes were charge isomers. The molecular weight of the normal enzyme was estimated at 110,000 by Sephadex G-200 chromatography in the absence of DTT, while that of the mutant was 53,000 . When $1.0 \mathrm{mM}$ DTT was added to the highly purified enzyme sample and to the elution buffer, the molecular weight of the residual ASB was increased to 100,000 , whereas that of the normal feline enzyme remained unchanged. In the presence of 1.0 $\mathrm{mM}$ cysteamine, the residual enzyme also had an estimated mol wt of 100,000 by gel filtration.

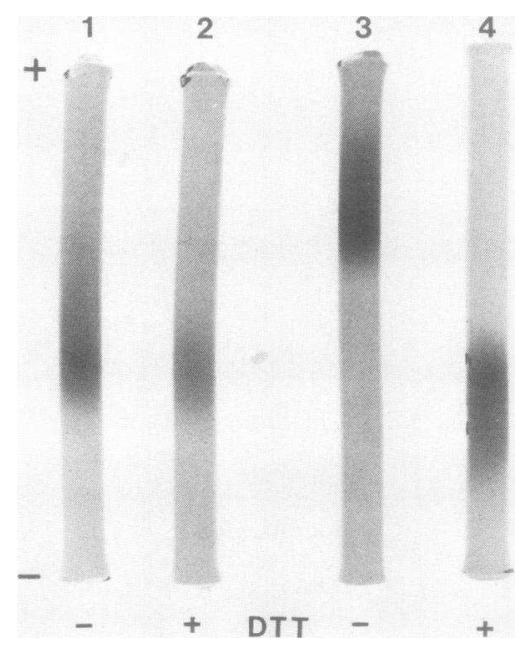

FIGURE 2 Analytical polyacrylamide gel electrophoresis of purified normal and feline MPS VI hepatic ASB \pm DTT. Gels 1 and 2 , normal feline ASB in the absence and presence of $1.0 \mathrm{mM}$ DTT, respectively. Gels 3 and 4, feline MPS VI ASB in the absence and presence of DTT, respectively. Samples were applied at the anode. 

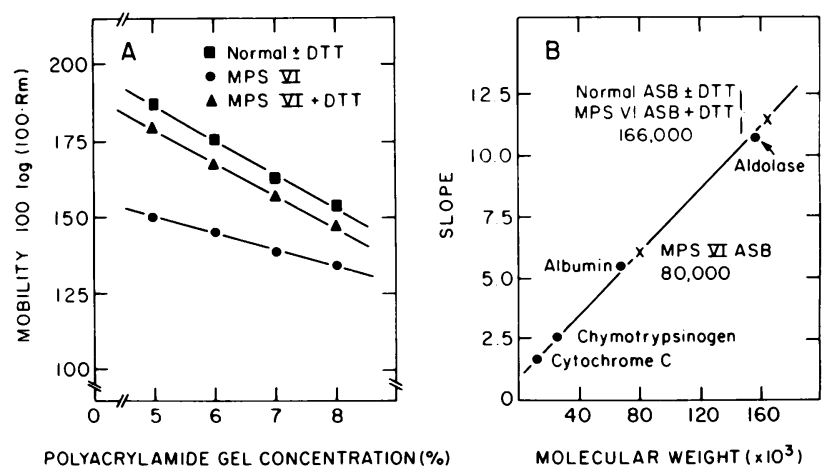

FIGURE 3 Estimation of the native molecular weights of normal and feline MPS VI hepatic ASB \pm DTT by polyacrylamide gel electrophoresis (18). (A) The effect of different gel concentrations on the mobility of normal feline and feline MPS VI ASB $\pm D T T$. Note that the slopes of the normal enzyme \pm DTT and the MPS VI enzyme+DTT are parallel indicating that they have the same molecular weights, but are charge isomers. The slope and mobility of the MPS VI enzyme - DTT is consistent with a different molecular weight and charge. (B) The indicated molecular weight estimates were determined from the slope-molecular weight relationship for the feline enzymes \pm DTT compared to protein standards (18). The feline enzymes \pm DTT are indicated (X). See text for details.

In vitro effect of thiol-reducing agents on MPS VI residual ASB. Tables IV and V summarize the changes in leukocyte ASB activity and dermatan sulfate concentration following incubation of whole blood samples from an 18-mo-old affected female cat and her normal female sibling with various concentrations of DTT and cysteamine (0.1-5 mM) for $1 \mathrm{~h}$ at $37^{\circ} \mathrm{C}$. The MPS VI leukocyte residual activity was increased up to 11- and 20-fold with DTT and cysteamine, respectively. Maximal stimulation of leukocyte residual activity occurred when either thiol reagent concentration in blood was $2 \mathrm{mM}$. The dermatan sulfate concentration in MPS VI leukocytes was markedly decreased $(\sim 5 \%$ of initial) or nondetectable at all concentrations of both sulfhydryl-reducing agents. A comparable increase in residual leukocyte activity and decrease in dermatan sulfate concentration was observed when whole blood was incubated with $5.0 \mathrm{mM}$ cystamine. In contrast, none of these reagents had a significant effect on the ASB activity in normal leukocytes.

In vivo effect of thiol-reducing agents on MPS VI $A S B$. Intravenous infusions of DTT $(50 \mathrm{mg} / \mathrm{kg})$ or cysteamine $(15 \mathrm{mg} / \mathrm{kg})$ were well tolerated by the animals. Heart and respiratory rates, as well as glucose and hemoglobin levels, remained stable throughout the infusions. No vomiting or seizure activity was observed.

Table VI compares the ASB activities and dermatan sulfate concentrations in leukocytes from the normal
TABLE IV

Effect of DTT on Normal and MPS VI Feline Leukocyte Arylsulfatase B Activities and Dermatan Sulfate Concentrations In Vitro

\begin{tabular}{ccccc}
$\begin{array}{c}\text { Concen- } \\
\text { tration }\end{array}$ & Normal & MPS VI & Normal & MPS VI \\
\hline$m M$ & $\%$ Initial ASB & activity & & \% Initial dermatan sulfate \\
levelt & \\
& & & & ND \\
None & 100 & 100 & ND & ND \\
0.1 & 100 & 170 & ND & ND \\
1.0 & 110 & 510 & ND & ND \\
2.0 & 110 & 1120 & ND & ND \\
5.0 & 110 & 810 & &
\end{tabular}

Heparinized whole blood $(30 \mathrm{ml})$ from normal and MPS VI cats was incubated with various concentrations of DTT for $1 \mathrm{~h}$ at $37^{\circ} \mathrm{C}$. The leukocytes were isolated, lysed in distilled water, and ASB activity and dermatan sulfate concentrations were determined as described in Methods.

- Initial ASB sp act were 341.9 and $49.2 \mathrm{nmol} / \mathrm{h}$ per $\mathrm{mg}$ protein in the normal and MPS VI leukocytes, respectively.

Initial dermatan sulfate concentration was $145 \mu \mathrm{g} / \mathrm{mg}$ protein in MPS VI leukocytes. No dermatan sulfate was detected (ND) in normal feline leukocytes within the sensitivity of the assay $(<0.01$ $\mu \mathrm{g} / \mathrm{mg}$ protein).

and MPS VI cats before and after intravenous administration of DTT. Immediately following infusion of DTT, the MPS VI residual ASB activity in leukocytes

TABLE V

Effect of Cysteamine and Cystamine on Normal and MPS VI Feline Leukocyte Arylsulfatase B Activities and Dermatan Sulfate Concentrations In Vitro

\begin{tabular}{lccccr}
\hline Thiol reagent & $\begin{array}{c}\text { Concen- } \\
\text { tration }\end{array}$ & Normal & MPS VI & Normal & MPS VI \\
\hline \multirow{2}{*}{ None } & $m M$ & \multicolumn{2}{c}{ \% Initial ASB } & \multicolumn{2}{c}{ \% Intial dermatan } \\
activity & & & sulfate levelf \\
Cysteamine & 0.1 & 100 & 600 & ND & ND \\
& 1.0 & 130 & 1,580 & ND & ND \\
& 2.0 & 120 & 2,070 & ND & 5 \\
& 5.0 & 110 & 1,680 & ND & 5 \\
Cystamine & 5.0 & 110 & 1,820 & ND & ND \\
\hline
\end{tabular}

Heparinized whole blood $(30 \mathrm{ml})$ from normal and MPS VI cats was incubated with various concentrations of cysteamine or with $5.0 \mathrm{mM}$ cystamine for $1 \mathrm{~h}$ at $37^{\circ} \mathrm{C}$. The leukocytes were isolated, lysed in distilled water, and ASB activity and dermatan sulfate concentrations were determined as described in Methods.

- Initial ASB sp act were 268 and $16 \mathrm{nmol} / \mathrm{h}$ per $\mathrm{mg}$ protein in the normal and MPS VI leukocytes, respectively.

† Initial dermatan sulfate concentration was $105 \mu \mathrm{g} / \mathrm{mg}$ protein in MPS VI leukocytes. No dermatan sulfate was detectable (ND) in normal feline leukocytes. 
TABLE VI

Effect of Intravenous Infusion of DTT on Normal and MPS

VI Feline Leukocyte Arylsulfatase B Activities and Dermatan Sulfate Concentrations

\begin{tabular}{rrrrr}
\hline Time & Normal & MPS VI & Normal & MPS VI \\
\hline \multicolumn{3}{c}{ \% Preinfusion ASB } & \multicolumn{2}{c}{ \% Preinfusion dermatan } \\
activity & & \multicolumn{2}{c}{ sulfate levelf } \\
Pre & 100 & 100 & ND & 100 \\
0 & 96 & 490 & ND & 73 \\
30 & 94 & 140 & ND & 92 \\
60 & 102 & 120 & ND & 100 \\
120 & 98 & 140 & ND & 100 \\
\hline
\end{tabular}

DTT $(50 \mathrm{mg} / \mathrm{kg}$ ) was administered intravenously over $10 \mathrm{~min}$ into an 18-mo-old MPS VI female cat $(2.27 \mathrm{~kg})$ and her normal sibling $(3.27 \mathrm{~kg})$. Heparinized blood samples were obtained immediately before and after infusion $(0,30,60$, and $120 \mathrm{~min})$. ASB activity and dermatan sulfate levels were determined in isolated leukocytes as described in Methods.

- Preinfusion ASB sp act were 758 and $14 \mathrm{nmol} / \mathrm{h}$ per $\mathrm{rng}$ protein in the normal and MPS VI leukocytes, respectively.

\ Preinfusion dermatan sulfate concentration was $64.0 \mu \mathrm{g} / \mathrm{mg}$ protein in MPS VI leukocytes. No dermatan sulfate was detected (ND) in the normal feline leukocytes.

was increased almost fivefold. A transient decrease occurred in the dermatan sulfate level at zero time, returning to preinfusion values at $30 \mathrm{~min}$.

When cysteamine was intravenously infused (Table VII), the residual activity was increased more than fourfold immediately after infusion, increasing to almost sevenfold at $30 \mathrm{~min}$, and then returning to preinfusion levels by $60 \mathrm{~min}$. Dermatan sulfate concentrations in peripheral leukocytes were decreased to $\sim 35 \%$ of preinfusion levels after infusion and remained at $\sim 45 \%$ of initial levels for at least $120 \mathrm{~min}$. In contrast, cysteamine had an inhibitory, if any, effect on normal ASB activity; dermatan sulfate in normal feline leukocytes remained undetectable.

\section{DISCUSSION}

Animal models of human inborn errors of metabolism provide the opportunity to characterize the molecular nature of the enzymatic defect, and based on these studies, to rationally design and evaluate various therapeutic strategies before human trials. Using this approach, the physical and kinetic properties of highly purified hepatic residual ASB from the MPS VI cats were determined. Compared with the purified normal feline hepatic enzyme, the MPS VI residual activity had a 100 -fold higher $K_{m}$, an altered electrophoretic mobility and half the native molecular weight. Notably, the residual enzyme was more thermo-, cryo-, and pH-labile, particularly when highly purified,
TABLE VII

Effect of Intravenous Infusion of Cysteamine on Normal and MPS VI Feline Leukocyte Arylsulfatase B Activities and Dermatan Sulfate Concentrations

\begin{tabular}{rrrrr}
\hline Time & Normal & MPS VI & Normal & MPS VI \\
\hline \multicolumn{3}{c}{ \% Preinfusion ASB } \\
actioti ${ }^{\bullet}$ & & \multicolumn{2}{c}{ \% Preinfusion dermatan } \\
sulfate levelf \\
Pre & 100 & 100 & ND & 100 \\
0 & 111 & 430 & ND & 34 \\
30 & 98 & 680 & ND & 39 \\
60 & 86 & 116 & ND & 46 \\
120 & 70 & 98 & ND & 46 \\
\hline
\end{tabular}

Cysteamine $(15 \mathrm{mg} / \mathrm{kg})$ was administered intravenously over 10 min into an 18-mo-old MPS VI female cat $(2.27 \mathrm{~kg})$ and her normal sibling $(3.27 \mathrm{~kg})$. Heparinized blood samples were obtained immediately before and after infusion $(0,30,60$, and $120 \mathrm{~min})$. ASB activity and dermatan sulfate levels were determined in isolated leukocytes as described in Methods.

- Preinfusion ASB sp act were 705 and $12 \mathrm{nmol} / \mathrm{h}$ per mg protein in the normal and MPS VI leukocytes, respectively.

$\downarrow$ Preinfusion dermatan sulfate concentration was $147 \mu \mathrm{g} / \mathrm{mg}$ protein in the MPS VI leukocytes. No dermatan sulfate was detected (ND) in normal feline leukocytes.

which prompted efforts to stabilize the enzyme. When the thiol-reducing reagent, DTT, was added to the highly purified residual enzyme, its activity was increased severalfold (Table II). This observation stimulated the evaluation of other sulfhydryl-reactive agents. Cysteamine, a strong reducing agent that also is lysosomotropic (19), markedly increased the residual activity whereas the alkylating and mercurial reagents were stimulatory, but to a lesser degree. Because these reagents had no effect or slightly inhibited the normal ASB activity, an investigation was undertaken to determine the effect of DTT, the prototype reducing agent, on the physical and kinetic properties of the purified normal feline and MPS VI residual activities.

Intriguingly, in the presence of DTT, the residual activity had an increased $\mathrm{V}_{\max }$ value and an electrophoretic mobility and native molecular weight similar to those of the normal enzyme (Figs. 1-3). In the presence of cysteamine, the native molecular weight of the residual activity also was similar to that of the normal enzyme. Previous studies of the purified native and denatured enzymes indicated that the MPS VI residual activity was a monomer, whereas the normal feline enyzme was a homodimer (10). Thus, the findings reported here suggest that DTT and cysteamine facilitated the dimerization of the residual enzyme. However, DTT did not alter the apparent $K_{m}$ or stability of the dimerized residual activity.

The following model is proposed to explain the effect of the thiol-reducing agents on the MPS VI resid- 
ual enzyme (Fig. 4). In the normal feline enzyme, spontaneous dimerization of the isologous subunits occurs to form the active homodimer. In feline MPS VI, we suggest that a point mutation in the structural gene results in the substitution of a cysteinyl residue at or near the substrate binding site-or a conformational change in the protein occurs due to a different amino acid substitution that alters substrate binding and, in addition, exposes a normally unavailable cysteine. This substituted or exposed cysteine forms an intramolecular disulfide bridge with another cysteinyl residue. The formation of this disulfide bridge causes a further conformational change that prevents subunit dimerization. In the presence of the thiol-reducing reagents, DTT and cysteamine, the disulfide bond is reduced, permitting subunit association as well as normalizing several other properties of the MPS VI enzyme (Table III).

Because DTT and cysteamine have been safely administered as experimental therapeutic agents in patients with cystinosis (19-25), the therapeutic use of these compounds was evaluated in the feline model. Initially, in vitro studies were undertaken to determine if thiol-induced dimerization could enhance the MPS VI residual ASB activity in leukocytes and catabolize the accumulated substrate. After incubation of fresh
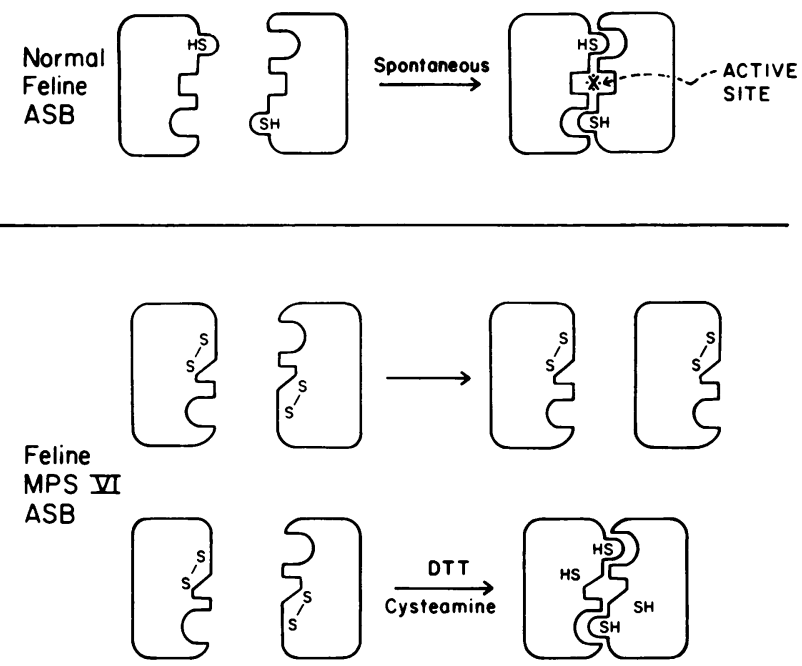

Figure 4 Schematic model for the thiol-induced dimerization of feline MPS VI residual ASB activity. (upper panel) The normal isologous subunits spontaneously dimerize to form the active homodimer. (center panel) Due to the structural gene mutation, a substituted cysteine or previously unavailable cysteinyl residue at or near the substrate binding site forms a disulfide bridge with another cysteine causing a further conformational change which prevents subunit dimerization. (lower panel) In the presence of DTT or cysteamine the disulfide bond is reduced allowing subunit association to occur, with a concomitant enhancement of residual ASB activity. See Discussion for details. heparinized whole blood with DTT or cysteamine, the leukocyte residual ASB activity was increased up to 11- and 20-fold, respectively, and, most importantly, the accumulated dermatan sulfate was degraded (Tables IV and V). Based on these encouraging in vitro results, in vivo trials were conducted. Intravenously administered DTT resulted in an immediate, but transient increase in leukocyte residual ASB activity and had little, if any, effect on the leukocyte dermatan sulfate levels (Table VI). In contrast, cysteamine infusion not only enhanced the residual leukocyte activity for at least $1 \mathrm{~h}$, but also resulted in the clearance of leukocyte dermatan sulfate; the accumulated substrate was reduced to $35 \%$ of the preinfusion level immediately after administration and remained at about $45 \%$ of the preinfusion level for the 120 -min period studied. The differential effectiveness of these thiolreducing reagents may have been due to the rapid inactivation (i.e., oxidation, plasma clearance, etc.) of DTT, whereas cysteamine, an aminothiol, may have been protected by its preferential uptake by lysosomes (19). The effectiveness of cysteamine and the fact that cystamine (the disulfide of cysteamine) enhanced the residual leukocyte activity in vitro (Table $\mathrm{V}$ ) suggest that the disulfide may be of therapeutic value because it is reduced to cysteamine presumably by glutathione or other reducing agents (19). In contrast to cysteamine, cystamine is odorless and colorless, which should facilitate its palatable inclusion in the feline diet.

In summary, these studies provide the prototype for the treatment of inborn errors by enhancement of the residual activity via subunit reassociation. This approach may be useful in the design of therapeutic endeavors in human diseases in which the enzymatic defect results from mutations that alter subunit association and enzyme function. Furthermore, these findings emphasize the value of characterizing the nature of the enzymatic defect, particularly in disorders with residual enzymatic activity, for the design of novel strategies to manipulate and therapeutically enhance the function and/or stability of the defective enzyme.

\section{ACKNOWLEDGMENTS}

The authors thank Mrs. Linda Lugo for her expert clerical assistance.

This work was supported in part from grants (AM 25759 GM 20138, and AM 25279), from the National Institutes of Health and a grant (1-578) from the March of Dimes Birth Defects Foundation. Dr. Vine is the recipient of a postdoctoral fellowship from the Institute for Pediatric Service of the Johnson \& Johnson Baby Products Company (New Brunswick, N. J.) and Ms. McGovern and Schuchman are recipients of National Institutes of Health predoctoral fellowships (1T32 HD07105). 


\section{REFERENCES}

1. Maroteaux, P., and M. Lamy. 1965. Hurler's disease, Morquio's disease, and related mucopolysaccharidoses. J. Pediatr. 67: 312-316.

2. Stumpf, D.A., J. H. Austin, A. C. Crocker, and M. LaFrance. 1973. Mucopolysaccharidosis type VI (Maroteaux-Lamy syndrome). Am. J. Dis. Child. 126: 747755.

3. Fluharty, A. L., R. L. Stevens, D. L. Sanders, and H. Kihara. 1974. Arylsulfatase B deficiency in MaroteauxLamy syndrome cultured fibroblasts. Biochem. Biophys. Res. Commun. 59: 455-461.

4. McKusick, V. A., E. F. Neufeld, and T. E. Kelly. 1978. The mucopolysaccharide storage diseases. In The Metabolic Basis of Inherited Disease. J. B. Stanbury, J. B. Wyngaarden, and D. S. Fredrickson, editors. McGrawHill Inc., New York. 1282-1307.

5. Jezyk, P. F., M. E. Haskins, D. F. Patterson, W. J. Mellman, and M. Greenstein. 1977. Mucopolysaccharidosis in a cat with arylsulfatase B deficiency: a model of Maroteaux-Lamy syndrome. Science (Wash., D. C.). 198: 834-836.

6. Haskins, M. E., P. F. Jezyk, and D. F. Patterson. 1979. Mucopolysaccharide storage disease in three families of cats with arylsulfatase B deficiency: leukocyte studies and carrier identification. Pediatr. Res. 13: 1203-1210.

7. Haskins, M. E., P. F. Jezyk, R. J. Desnick, and D. F. Patterson. 1980. Feline models of mucopolysaccharidosis. In Enzyme Therapy in Genetic Diseases: 2. R. J. Desnick, editor. Alan R. Liss, Inc., New York. 393-414.

8. Shapira, F., R. R. DeGregorio, R. Matalon, and H. L. Nadler. 1975. Reduced arylsulfatase B activity of the mutant enzyme protein in Maroteaux-Lamy syndrome. Biochem. Biophys. Res. Commun. 62: 448-455.

9. McGovern, M. M., D. T. Vine, M. E. Haskins, and R. J. Desnick. 1981. An improved method for heterozygote identification in feline and human mucopolysaccharidosis VI, arylsulfatase B deficiency. Enzyme. 26: 206-210.

10. Vine, D. T., M. M. McGovern, M. E. Haskins, and R. J. Desnick. 1981. Feline mucopolysaccharidosis VI: purification and characterization of the residual arylsulfatase B activity. Am. J. Hum. Genet. 33: 916-927.

11. Percy, A. K., and R. O. Brady. 1968. Metachromatic leukodystrophy: diagnosis with samples of venous blood. Science (Wash., D. C.). 161: 594-595.

12. Bradford, M. M. 1976. A rapid and sensitive method for quantitation of microgram quantities of protein using the principle of protein-dye binding. Anal. Biochem. 72: 248-254.

13. Schuchman, E. H., and R. J. Desnick. 1981. A new, improved continuous monodimensional electrophoretic system for the separation and quantitation of individual glycosaminoglycans. Anal. Biochem. 117: 419-426.

14. Bohlen, P., S. Stein, W. Pairman, and S. Udenfriend. 1973. Flurometric assay of proteins in the nanogram range. Arch. Biochem. Biophys. 155: 213-220.

15. Kimura, A., K. Tsurumi, and S. Ogane. 1974. Studies on urinary glycosaminoglycans: a simple method for the determination of urinary acidic glycosaminoglycans by electrophoresis on cellulose acetate paper. In The Biochemistry and Pathology of Connective Tissue. Y. Otaka, editor. Igaku Sloin Ltd. Tokyo. 36-47.

16. Reisfeld, R. A., U. J. Lewis, and D. F. Williams. 1962. Disc electrophoresis of proteins and peptides on polyacrylamide gels. Nature (Lond.). 195: 281-283.

17. Hendrick, J. L., and A. J. Smith. 1968. Size and charge isomer separation and estimation of molecular weights of proteins by disc gel electrophoresis. Arch. Biochem. Biophys. 126: 155-164.

18. Thoene, J. G., R. G. Oshima, J. C. Crawhall, D. L. Olson, and J. A. Schneider. 1976. Cystinosis: intracellular cystine depletion by aminothiols in vitro and in vivo. $J$. Clin. Invest. 58: 180-189.

19. Goldman, H., C. R. Scriver, K. Aaron, and L. Pinsky. 1970. Use of dithiothreitol to correct cystine storage in cultured cystinotic fibroblasts. Lancet. I: 811-812.

20. Goldman, H., C. R. Scriver, K. Aaron, E. Devlin, and Z. Canlas. 1971. Adolescent cystinosis: Comparisons with infantile and adult forms. Pediatrics. 47: 979-988.

21. Aaron, K., H. Goldman, and C. R. Scriver. 1971. Cystinosis; new observations: 1 . Adolescent (Type III) form. 2. Correction of phenotypes in vitro with dithiothreitol. In Inherited Disorders of Sulphur Metabolism. N. A. J. Caroon and D. N. Raine, editors. Williams and Wilkins Co., Baltimore, Md. 150-161.

22. DePape-Brigger, D., H. Goldman, C. R., Scriver, E. Devlin, and O. Maimer, 1977. The in vivo use of dithiothreitol in cystinosis. Pediatr. Res. 11: 124-131.

23. Girardin, E. P., M. S. DeWolfe, and J. F. S. Crocker. 1979. Treatment of cystinosis with cysteamine. J.Pediatr. 94: 838-840.

24. Yudkoff, M., J. W. Foreman, and S. Segal. 1981. Effect of cysteamine therapy in nephropathic cystinosis. $N$. Engl. J. Med. 304: 141-145. 